\title{
Improvement in short-term streamflow forecasting using an integrated modelling framework
}

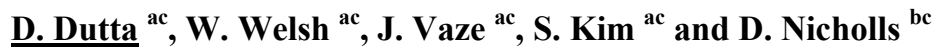 \\ ${ }^{a}$ CSIRO Water for a Healthy Country National Research Flagship, CSIRO Land and Water GPO Box 1666, \\ Canberra, ACT 2601, Australia \\ ${ }^{b}$ DA Nicholls Pty Ltd, Nicholls, ACT 2913, Australia \\ ${ }^{c}$ eWater Cooperative Research Centre, University of Canberra, ACT 2601, Australia \\ Email: dushmanta.dutta@csiro.au
}

\begin{abstract}
Short-term streamflow forecasting is a crucial element in any regulated river system operation. The multiple benefits from an improved streamflow forecasting capability include: (i) an enhanced ability to predict the volumes and timing of flood events, (ii) improved water use efficiency through better anticipation of river inflows (particularly associated with inflows from unregulated tributaries), (iii) a concomitant reduction in operational losses due to over releases from water storages, and (iv) fewer shortfalls in supplying water orders.

Over the past few decades, many numerical streamflow prediction techniques using observed time series (TS) have been developed and widely used in water resources planning and management. Recent advances in quantitative rainfall forecasting by numerical weather prediction (NWP) models have made it possible to produce improved streamflow forecasts using continuous rainfall-runoff (RR) models. In the absence of a suitable integrated system of NWP, RR and river system models, river operators in Australia mostly use spreadsheet-based tools to forecast streamflow using gauged records. The eWater Cooperative Research Centre of Australia has recently developed a new generation software package called Source Integrated Modelling System (Source IMS), which allows a seamless integration of continuous RR and river system models for operational and planning purposes.
\end{abstract}

A study was undertaken using Source IMS for a comparative evaluation of streamflow forecasting methods on a regulated section of the Murray River, a major stream in the Murray-Darling Basin, Australia. The methods include three TS based linear techniques and, RR models of two selected unregulated sub-basins that drain into the river reach. The results were compared using three statistical indicators with the actual forecasts made by the Murray river operators and the observed data. The results show that while streamflow forecasts by the river operators were reasonably accurate up to day 3 and traditional TS based approaches were reasonably accurate up to 2 days, well calibrated RR models can provide better forecasts for longer periods when using high quality quantitative precipitation forecasts. The river operators tended to underestimate large magnitude flows. This paper presents the outcomes from the case study. The uncertainty associated with forecasts using different datasets and methods and, potential operational benefits of the shortterm streamflow forecasts are also discussed.

Keywords: Streamflow forecast, Source Integrated Modelling System, Time series linear model, Numerical weather prediction model, Rainfall-runoff model, Murray River system 
Dutta et al., Improvement in short-term streamflow forecasting using an integrated modelling framework

\section{INTRODUCTION}

Many activities involving water resource systems require streamflow forecasts. Linear models based on observed time series (TS) have been used in water resources management for the past several decades to forecast streamflows. Linear TS models can be classified in two categories depending on the number of TS involved in the model: a) single variable models and b) models using exogenous variables. Two widely used TS linear models are Auto-Regressive (AR) and Auto-Regressive Moving Averages (ARMA) models. A variation of the ARMA model is the Auto-Regressive Integrated Moving Average (ARIMA) model. The name "Box \& Jenkins methods" is commonly used when one of the ARMA methods is used (Box and Jenkins, 1970). An ARMA model with exogenous or independent variables (e.g., rainfall) is called an ARMAX model (Box and Pierce, 1970). Many research investigations have been conducted to evaluate the efficiency of these methods in different catchments around the World (Vicens et al. 1975; Newbold 1981; Awwad and Valdes 1992; Tang et al. (1991). General consensus is that among TS methods with a long memory, Box \& Jenkins methods have the best performance.

Whilst TS analysis still plays an important role in streamflow forecasts using linear models, a number of studies have suggested that it is possible to improve the accuracy of probabilistic streamflow forecasts, particularly short-term forecasts, using meteorological forecasts by numerical weather prediction (NWP) models (Anderson et al., 2002; Koussis et al., 2003; Clark and Hay, 2004; Tucci and Collischonn, 2006). For many years in Australia, the National Meteorological and Oceanographic Centre (NMOC) of the Bureau of Meteorology (BoM) ran NWP models to provide a suite of analysis and prediction products (BoM, 2009). Whilst the accuracy of weather forecasts has steadily improved over the years, it has been challenging to integrate quantitative precipitation forecasts (QPF) into flood forecasting operations, which require suitable techniques, such as hydrological models, to translate the rainfall to streamflow (Collischonn et al., 2005; Tucci and Collischonn 2006; Cuo and Pagano, 2011). Gouweleeuw et al. (2009) conducted an analysis of flood forecasting using QPF from several of the BoM's NWP models and found that QPF from NWP model output data can assist in early flood detection when used with a well calibrated hydrological model. In the absence of a suitable integrated system of NWP models and well calibrated hydrological models for streamflow prediction, river operators in Australia mostly use gauged flow data to forecast streamflow using spreadsheet based tools.

The eWater Cooperative Research Centre of Australia has recently developed a new generation river system software package called the Source Integrated Modelling System (Source IMS) for operational and planning purposes in regulated and unregulated river systems (Welsh et al., 2011). In this study, the Source IMS is used to undertake an evaluation of streamflow forecasts by continuous RR models with QPF and three TS based linear forecasting techniques, namely: AR, ARMA and ARMAX models with historical data for two selected unregulated river basins in the Murray River system in the Murray-Darling Basin (MDB). The forecasts by these techniques were statistically compared with the actual Murray river operator forecasts and recorded gauged flow to evaluate their performances.

\section{METHODOLOGY}

\subsection{Source Integrated Modelling System}

The Source IMS provides tools for the prediction and quantification of water and associated constituents from catchments to the estuary. The components used to model regulated rivers within the Source IMS encompass (and enhance) the key functionalities of the three widely used river system modelling tools in Australia: IQQM (Simons et al., 1999), REALM (Perera, 2005) and MSM-Bigmod (Close, 1986), as well as new scientific research. The physical and regulatory processes and management rules of a regulated river system are conceptualised in six major components within the Source IMS simulation engine: Catchment runoff; River system network; Interactions between river and groundwater systems; River regulation and storages; Demands (urban, irrigation and environmental) and Complex river management rules. Each of these includes several subcomponents to comprehensively represent the underlying processes, rules and regulations. The various components and their functionalities are elaborated in Welsh et al. (2011). The system as a whole is extensible through expression editor and plug-ins functionalities, which can be used to add new modelling components that are not otherwise available in the system.

The Source IMS includes three scenario modes: catchment runoff (hereafter termed Source catchment), river manager (hereafter termed Source RM) and river operator (hereafter termed Source RO). Source Catchment includes a conceptual RR modelling framework for estimating catchment water yield and runoff 
Dutta et al., Improvement in short-term streamflow forecasting using an integrated modelling framework

characteristics. The framework currently provides the user with an option to choose from six conceptual daily RR models: AWBM (Boughton, 2004), IHACRES (Croke et al., 2006), Sacramento (Burnash et al., 1973), SIMHYD (Chiew et al., 2002), SMARG (Vaze et al., 2004) and GR4J (Perrin et al., 2003). These models can be calibrated using observed climate and streamflow data in the gauged catchments using a combination of objective functions and optimisation methods. Outputs from NWP models can be dynamically linked to Source Catchment for streamflow forecasting. Source $R O$ is primarily designed for river system operators to forecast and route flow for daily river operations. Source IMS allows users to incorporate user-specified forecasting techniques in Source $R O$ through plug-ins.

\subsection{Quantitative Precipitation Forecasts by NWP Models}

The NMOC of the BoM runs several NWP models to generate a suite of analysis and prediction products. These models operate at a range of temporal and spatial resolutions, different spatial domains and with varying forecast lead times (BoM, 2009). The BoM used the GASP, LAPS, TXLAPS and MESOLAPS NWP models until 2009. In 2009, the BoM developed a new system of NWP models called ACCESS (Australian Community Climate and Earth-System Simulator). In 2010, ACCESS replaced the GASP, LAPS, TXLAPS and MESOLAPS NWP systems (BoM, 2010). In this study, QPF by LAPS and ACCESS-R were used.

\subsection{Traditional Time Series Analysis Methods}

The mathematical expressions of the three traditional linear TS models used in the study are shown in Table 1. The notation $\operatorname{AR}(p)$ refers to an $\operatorname{AR}$ model of order $p \cdot \operatorname{ARMA}(p, q)$ refers to an $\operatorname{ARMA}$ model, where $p$ is the order of the autoregressive part and $q$ is the order of the moving average part. The notation of ARMAX model is $\operatorname{ARMAX}(p, q, b)$, which refers to the model with $p$ autoregressive terms, $q$ moving average terms and $b$ exogenous input terms.

Table 1: Mathematical expressions of three TS linear models: AR, ARMA and ARMAX

\begin{tabular}{|l|l|l|}
\hline $\operatorname{AR}(p)$ & $\operatorname{ARMA}(p, q)$ & $\operatorname{ARMAX}(p, q, b)$ \\
\hline $\mathrm{X}_{\mathrm{t}}=c+\sum_{i=1}^{p} \varphi_{\mathrm{i}} \mathrm{X}_{\mathrm{t}-\mathrm{i}}+$ & $\mathrm{X}_{\mathrm{t}}=c+\varepsilon_{\mathrm{t}}+\sum_{i=1}^{p} \varphi_{\mathrm{i}} \mathrm{X}_{\mathrm{t}-\mathrm{i}}+\sum_{i=1}^{q} \theta_{\mathrm{i}} \varepsilon_{\mathrm{t}-\mathrm{i}}$ & $\mathrm{X}_{\mathrm{t}}=\varepsilon_{\mathrm{t}}+\sum_{i=1}^{p} \varphi_{\mathrm{i}} \mathrm{X}_{\mathrm{t}-\mathrm{i}}+\sum_{i=1}^{q} \theta_{\mathrm{i}} \varepsilon_{\mathrm{t}-\mathrm{i}}+\sum_{i=1}^{b} \eta_{\mathrm{i}} \mathrm{d}_{\mathrm{t}-\mathrm{i}}$ \\
$\varepsilon_{\mathrm{t}}$ &
\end{tabular}
Where, $\varphi_{1}, \ldots . ., \varphi_{\mathrm{p}}$ and $\theta_{1}, \ldots, \theta_{q}$ are the parameters of the model, $c$ is a constant, $\varepsilon_{\mathrm{t}}, \varepsilon_{\mathrm{t}-1}, \ldots$ are white noise error terms and $\eta_{1}, \ldots . ., \eta_{\mathrm{b}}$ are
the parameters of the exogenous input $d_{t}$. The constant term is omitted by many for simplicity.

\subsection{Methods for statistical analysis}

The coefficient of determination $\left(R^{2}\right)$, Table 2: Statistical indices for analysis of model performance mean absolute error (MAE) and mean \begin{tabular}{|l|l|l|} 
Coefficient of determinant & Mean Absolute & Mean Absolute Percentage \\
\hline
\end{tabular} absolute percentage error (MAPE) were used to evaluate the forecasts. The equations of $\mathrm{R}^{2}$, MAE and MAPE are shown in Table $2 . \mathrm{R}^{2}$ ranges from 0 to 1 , with higher values indicating less error variance. The MAE is a quantity used to measure how close forecasts or predictions

\begin{tabular}{|c|c|c|}
\hline $\begin{array}{c}\text { Coefficient of determinant } \\
\left(\mathbf{R}^{2}\right)\end{array}$ & $\begin{array}{l}\text { Mean Absolute } \\
\text { Error (MAE) }\end{array}$ & $\begin{array}{c}\text { Mean Absolute Percentage } \\
\text { Error (MAPE) }\end{array}$ \\
\hline $1-\frac{\sum_{i=1}^{n}\left(Y_{i}^{o b s}-Y_{i}^{s i m}\right)^{2}}{\sum_{i=1}^{n}\left(Y_{i}^{o b s}-\hat{y}\right)^{2}}$ & $\frac{1}{\mathrm{n}} \sum_{i=1}^{n}\left|Y_{i}^{o b s}-Y_{i}^{s i m}\right|$ & $\sqrt{\frac{1}{\mathrm{n}} \sum_{i=1}^{n}\left|\frac{Y_{i}^{o b s}-Y_{i}^{s i m}}{Y_{i}^{\text {obs }}}\right|}$ \\
\hline obs: & & \\
\hline
\end{tabular}
are to the eventual outcomes. MAPE is a variation of MAE, and usually expresses accuracy as a percentage. A MAPE of zero indicates a perfect fit.

\section{STUDY AREA}

The upper part of the Murray River system from Hume Dam downstream to Yarrawonga Weir was selected as the case study area (Figure 1). There are two major unregulated river basins, Kiewa and Ovens, located between the Hume Dam and the Mulwala Lake. The total area of the Kiewa basin is about 1,749 $\mathrm{km}^{2}$. The Ovens basin covers an area of about $7,813 \mathrm{~km}^{2}$. These two basins contribute a significant amount of inflow to the Murray River.

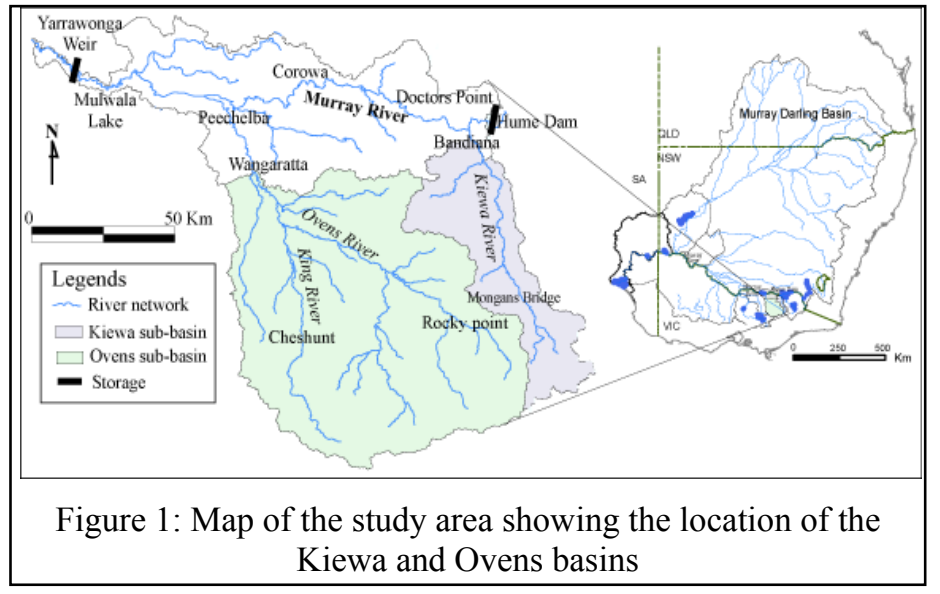


Dutta et al., Improvement in short-term streamflow forecasting using an integrated modelling framework

\section{SIMULATION}

The Source IMS was set up to simulate runoff from the Kiewa and Ovens basins using the selected forecast techniques, namely: the RR models built into the Source IMS and the AR, ARMA and ARMAX models. For the comparative analysis, the gauging stations at Bandiana in the Kiewa basin and at Wangaratta in the Ovens basin were selected based on the availability of long-term gauged data. A total of 74 operator forecast events between 2000-2010 were identified from the Murray river operators' spreadsheets. The Murray river operators use cell formulas to forecast the inflows from the Kiewa and Oven's rivers. The formulas apply spread factors to the daily observed flows at upstream gauging stations, and a value for losses. The observations at Mongans Bridge on the Kiewa River are used to forecast the flow at Bandiana, whereas the observations at Cheshunt on the King River and Rocky Point on the Ovens River are used to forecast flow at Wangaratta. The river operators have different formulas for winter/summer and low $/ \mathrm{medium} / \mathrm{high}$ flow periods. Switching between formulas is a manual process and dependent on the operator's judgment. During rainfall events it is not uncommon for the operator to override the forecast cell formula with a new value, usually based on historical records from similar rainfall events.

The six RR models of Source catchment were calibrated against the observed flow data at Bandiana and Wangaratta prior to their application in the streamflow forecasting. The statistical package, R, was initially used to estimate the parameters for the AR, ARMA and ARMAX models for the selected forecast events using methods based on the Kalman filter. The optimal orders of AR and ARMA for the selected forecast events were established by analysing the Akaike Information Criteria (Akaike, 1973). Observed rainfall from the previous time step was used as the exogenous variable for the ARMAX model. The established models were then incorporated into a Source $R O$ scenario using the Expression Editor functionality of the software package. The simulated streamflows by different models were compared with the forecasts made by river operators and the gauged data.

\subsection{Calibration of RR Models}

The calibration results for the six Table 3. Calibration statistics (NSE and Water Balance Error) for the RR models for both basins are six RR models

summarised in Table 3. There are marginal differences in the calibration NSE and water balance error (WBE) between the six models. These differences provide

\begin{tabular}{|l|l|c|c|c|c|c|c|}
\hline Basin & & AWBM & GR4J & IHACRES & Sacramento & SIMHYD & SMARG \\
\hline \multirow{2}{*}{ Kiewa } & NSE & 0.81 & 0.81 & 0.80 & 0.78 & 0.84 & 0.79 \\
\cline { 2 - 8 } & WBE (\%) & 1.30 & -1.79 & -2.53 & -5.72 & 0.68 & -3.08 \\
\hline \multirow{2}{*}{ Ovens NSE } & 0.85 & 0.94 & 0.83 & 0.93 & 0.88 & 0.90 \\
\cline { 2 - 8 } & WBE (\%) & 1.78 & -0.55 & -0.21 & 0.67 & 3.66 & 3.22 \\
\hline
\end{tabular}
an indication of the uncertainty introduced into the modelling results due to utilising different RR models (conceptually similar but with different model structures) with the same input climate and streamflow data. The calibration NSE for the six models in the Kiewa basin varies between 0.78 and 0.84 with a median of 0.81 ; the WBE varies from $1.3 \%$ to $5.72 \%$ with a median of $2.16 \%$. The results for the Ovens basin, and the validation results for both the catchments, show similar variability to the calibration results for the Kiewa basin. The RR models that performed best in the calibration (i.e., SIMHYD for Bandiana and GR4J for Wangaratta) were selected for streamflow forecasts. The observed rainfall was used as the input in the RR model assuming that the rainfall forecast was equal to the observed rainfall ("Perfect rainfall forecast"). The QPF by two different NWP models (LAPS and ACCESS-R) were subsequently used in the RR model. LAPS and ACCESS-R provided QPF of up to 3 days at an hourly resolution. They were converted to a daily resolution by matching the forecast and observed periods. Based on the availability of data, QPF by the LAPS model was used for the period of 2005-2006 and ACCESS-R for 2010.

\section{RESULTS}

The $\mathrm{R}^{2}$, MAE and MAPE values for the selected forecast techniques, including the operator forecasts for the selected 74 events between 2001-2010, are presented in Tables 4(a) \& (b) for Bandiana and Wangaratta, respectively. For the RR models, these values are based on the simulated streamflow using the perfect rainfall forecast. It can be observed from the tables that the predictions for different forecast days by the AR, ARMA and ARMAX models were similar. Whilst the ARMAX model provided better results for Bandiana, the AR model results were slightly better for Wangaratta. The improvement in forecast by ARMAX with the observed rainfall as the exogenous variable was not found to be very significant. The variation in the outputs from the TS approaches was much smaller compared to the other two methods. Hence, the ARMA model results were used as the representative outcomes from the three TS approaches for the rest of the analysis. The operator forecast at Bandiana for day 1 shows a good correlation with the observed data with a $\mathrm{R}^{2}$ value of 0.83 and can be considered to be reasonably accurate with MAPE below $20 \%$. However, the quality of the 
Dutta et al., Improvement in short-term streamflow forecasting using an integrated modelling framework

operator forecast progressively decreases with subsequent forecast days. On day 2 , the $\mathrm{R}^{2}$ value was much lower and the MAPE increased to over 20\%. The operator forecast showed a good correlation with the observed data up to day 5 at Wangaratta, however, the MAE and MAPE values were relatively high from day 3 onwards. The forecast by the ARMA model shows a high correlation with the observed data for day 1 for both locations with $\mathrm{R}^{2}$ ranging between 0.86-0.90. The MAPE of the ARMA model forecast for day 1 was relatively lower at Bandiana. The ARMA model forecast showed good correlation with the observed data for day 2 at Bandiana with a $\mathrm{R}^{2}$ value of 0.79 , but the MAPE was above $21 \%$. The ARMA model forecast at Wangaratta was of lower quality with $37 \%$ MAPE and a $\mathrm{R}^{2}$ value of 0.51 . The ARMA model forecast became less reliable at both locations for the subsequent days with a significant reduction in $R^{2}$ values and increase in MAPE. The RR model forecasts at both locations were consistent for the entire forecast period compared to the other two methods. The RR model forecast shows a high correlation with the observed data for the entire period with $\mathrm{R}^{2}$ values ranging between 0.74-0.86 at Bandiana and between 0.85-0.91 at Wangaratta. The MAPE values ranged between 7-17\% at Bandiana and between 22-30\% at Wangaratta for the forecast period.

Table 4: A comparison of forecasts by the Murray river operator, RR, AR, ARMA and ARMAX models

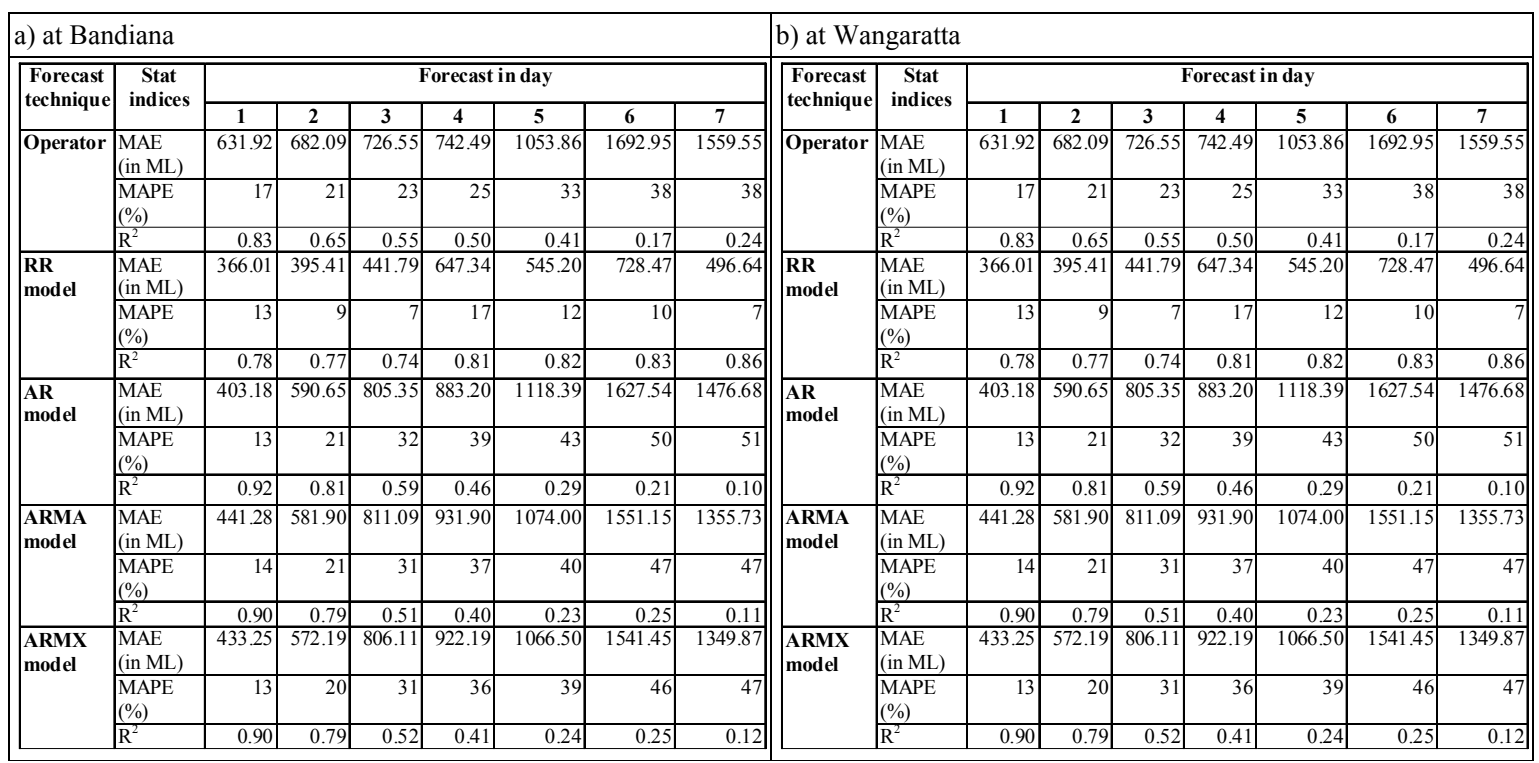

From these results, it can be inferred that while the operator forecast showed better agreement with the observed flow up to day 2 at Bandiana and up to day 3 at Wangaratta, beyond that the RR model produced outputs with a higher degree of accuracy with "perfect rainfall forecast". It is noted that the accuracy of the outcome of the RR model is highly dependent on the selection of the model and its proper calibration. The NSE values of the two selected RR models varied between $0.84-0.93$ for the two basins. This indicates that a reduction of uncertainty in RR model calibration can in turn reduce the uncertainty in forecasts.

Figure 3 shows a statistical comparison between the operator forecast and the forecast by the RR model at Bandiana with QPF from LAPS and ACCESS-R. The level of accuracy of the streamflow forecast by the RR model with LAPS and ACCESS-R QPF is found to be relatively lower, which can be attributed to the maximum and average volume differences between the observed rainfall and QPF during the periods of the selected events as shown in Table 5. The MAE and MAPE of forecasts by the RR model with LAPS QPF were better than that with QPF from ACCESS-R. However, the forecast by the RR model with QPF from ACCESS-R showed a better correlation. It is worth noting that these two sets of results are from different periods with different numbers of events and flow magnitude ranges. From these results, it is clear that there is still significant uncertainty involved with QPF by different NWP models.

Table 5: Volumetric differences of observed rainfall and QPF by LAPS and ACCESS-R at Bandiana

\begin{tabular}{|l|l|r|r|r|}
\hline $\begin{array}{l}\text { Volumetric } \\
\text { difference } \\
\text { (in mm) }\end{array}$ & NWP model & \multicolumn{3}{|c|}{ Forecast in Day } \\
\cline { 2 - 5 } & & $\mathbf{1}$ & $\mathbf{2}$ & $\mathbf{3}$ \\
\hline Average & LAPS & -6.39 & -1.95 & -4.79 \\
\cline { 2 - 5 } & ACCESS-R & -0.47 & -1.76 & 0.72 \\
\hline \multirow{2}{*}{ Max } & LAPS & 5.90 & 6.91 & 5.09 \\
\cline { 2 - 5 } & ACCESS-R & 2.75 & 0.08 & 11.85 \\
\hline
\end{tabular}



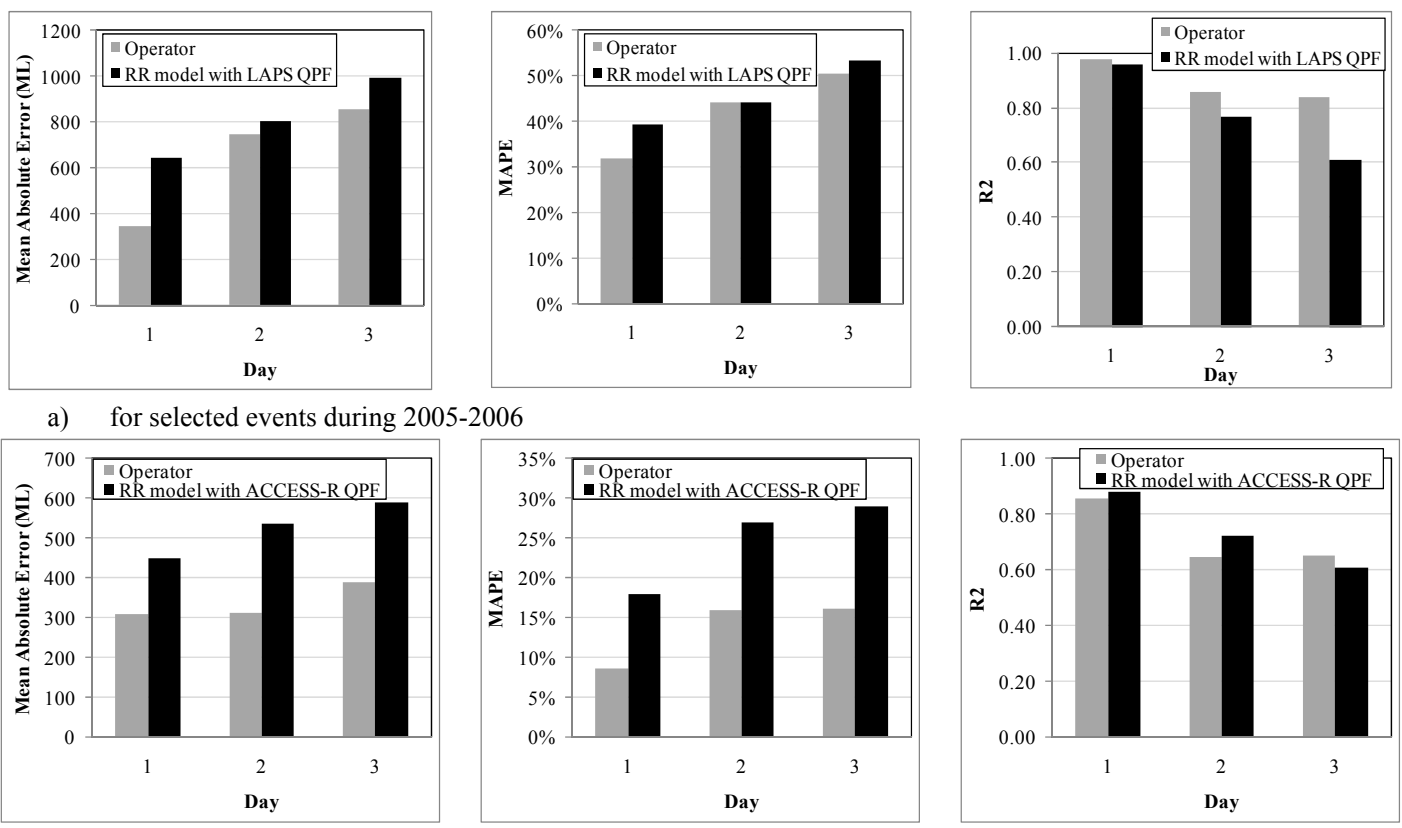

b) for selected events in 2010

Figure 3: A statistical comparison of streamflow forecasts at Bandiana by the Murray river operator compared to the RR model with LAPS and ACCESS-R QPF

Although the performance of NWP models in QPF has been improving over time (BoM, 2010), consistent performance for different seasons and weather systems is still a major challenge due to the enormous variability in space and time of the variables (Golding, 2000). According to Demeritt et al. (2007), NWP ensemble prediction systems exhibit greater forecast skill than any single NWP model control run or deterministic model run; ensembles increase forecast accuracy and allow for better accuracy in predictions at longer lead-times.

\section{CONCLUSIONS}

The paper presented the outcomes from a study conducted using the Source IMS to undertake a comparative evaluation of streamflow forecasts of up to 7 days using RR models and three TS based linear models at Kiewa and Ovens basins in the upper Murray River system. The results were compared with the actual forecasts made by the Murray river operator and the observed flow data. The TS models have provided reasonably good forecasts up to day 2 , however, their performance was not reliable beyond that. The river operator forecasts were reliable up to day 3 . The reliability reduces significantly beyond that. The study has demonstrated that a well calibrated RR model can provide accurate forecasts when using high quality quantitative precipitation forecasts. While the forecasts by the RR model with QPF from LAPS and ACCESS-R are promising, the uncertainty is still significant. It should be possible to further improve the forecasts by using NWP ensemble prediction systems with dynamic calibration of the RR models.

\section{ACKNOWLEDGEMENT}

The following persons are gratefully acknowledged for their contributions:

Andrew Bishop, MDBA, for the Murray river system operators' spreadsheets, Tom Pagano, CSIRO, for NWP data from WIRADA project, and Kerrie Tomkins, CSIRO, for very useful review comments.

\section{REFERENCES}

Akaike H (1973). Information Theory and an Extension of the Maximum Likelihood Principle, Proceedings of the $2^{\text {nd }}$ International Symposium on Information Theory, Akademia Kiado, Budapest, pp. 267-281

Anderson ML, Z-Q Chen, ML Kavva, A Feldman (2002). Coupling HEC-HMS with atmospheric models for prediction of watershed Runoff, Journal of Hydrologic Engineering, 7(3):312-318.

Awwad HM and JB Valdes (1992). Adaptive parameter estimation for multisite hydrologic forecasting, Journal of Hydraulic Engineering, ASCE, 118(9):1201-1221.

BoM (2009). NMOC Operations Bulletin No. 78, Bureau of Meteorology, Australian Government, 6p. 
Dutta et al., Improvement in short-term streamflow forecasting using an integrated modelling framework

BoM (2010). Operational implementation of the ACCESS Numerical Weather Prediction systems, NMOC Operations Bulletin No. 83, Bureau of Meteorology, Australian Government, 34p.

Box GEP and GM Jenkins (1970): Time Series Analysis Forecasting and Control, San Fracisco; Holden-Day.

Box GEP and DA Pierce (1970): Distribution of the residual autocorrelations in autoregressive-integrated moving average time series models, Journal of American Statistical Association, 65:1509-1526.

Boughton, WC (2004). The Australian water balance model. Environmental Modelling and Software, 19:943-956.

Burnash, RJC, RL Ferral, and RA McGuire (1973). A Generalised Streamflow Simulation System Conceptual Modelling for Digital Computers. Joint Federal and State River Forecast Center, Sacramento, Technical Report, 204 pp.

Chiew, FHS, MC Peel, and AW Western (2002). Application and testing of the simple rainfall-runoff model SIMHYD. In: Singh, V. P. and Frevert, D. K., (eds.), Mathematical Models of Small Watershed Hydrology and Applications. Water Resources Publications, Littleton, USA, pp. 335-367.

Clark, M and LE Hay (2004). Use of Medium-Range Numerical Weather Prediction Model Output to Produce Forecasts of Streamflow, Journal of Hydrometeorology, 5:15-32.

Close, AF (1986), Computer Modelling of the River Murray, In Hydrology and Water Resource Symposium, Griffith University, Brisbane, November 1986.Croke, BFW, F Andrews, AJ Jakeman, SM Cuddy, A Luddy (2006). IHACRES Classic Plus: A redesign of the IHACRES rainfall-runoff model, Environmental Modelling and Software, 21:426-427.

Collischonn W, R Haas, I Andreolli, CEM Tucci (2005). Forecasting River Uruguay flow using rainfall forecasts from a regional weather-prediction model, Journal of Hydrology, 205:87-88.

Cuo L and T Pagano (2011) A Review of Quantitative Precipitation Forecasts and Their Use in Short- to Medium-Range Streamflow Forecasting, Journal of Hydrometeorology, doi: 10.1175/2011JHM1347.1.

Demeritt, D, H Cloke, F Pappenberger, J Thielen, J Bartholmes, M-H Ramos (2007). Ensemble predictions and perceptions of risk, uncertainty, and error in flood forecasting. Environ. Hazards, 7(2):115-127.

George B, R Adams, D Ryu, AW Western, P Simon and B Nawarathna (2011). An Assessment of Potential Operational Benefits of Short-term Stream Flow Forecasting in the Broken Catchment, Victoria, Proceedings of the $34^{\text {th }}$ IAHR World Congress, Brisbane, Australia.

Golding, BW (2000). Quantitative precipitation forecasting in the UK. JOurnal of Hydrology, 239, 286-305.

Gouweleeuw BT, GP Leahy and AH Weerts (2009). Quantitative precipitation forecast and early warning: the Hunter Valley flood of June 2007, Proceedings of the 18th World IMACS/MODSIM Congress, Cairns, Australia, 3711-3717.

Koussis AD, K Lagouvardos, K Mazi, V Kotroni, D Sitzmann, J Lang, H Zaiss, A Buzzi, P Malguzzi (2003). Flood forecasts for urban basins with integrated hydro-meteorological model, Journal of Hydrologic Engineering, 8(1): 1-11.

Newbold, P (1981). Some recent developments in time series analysis, International statistical Review, 49:53-66.

Perera, BJC, B James and MDU Kularathna (2005), Computer software tool REALM for sustainable water allocation and management, Journal of Environmental Management, 77(4): 291-300.

Perrin C, C Michel, V Andreassian (2003). Improvement of a parsimonious model for streamflow simulations. Journal of Hydrology, 279, 275-289.

Simons, M, G Podger, R. Cooke (1996), IQQM - A hydrologic modelling tool for water resource and salinity management, Environmental Software, 11(1-3):185-192.

Tang Z, C de Almeida, PA Fishwick (1991). Time series forecasting using neural networks vs. Box-Jenkins methodology, SIMULATION, 303-310.

Tucci CEM and W Collischonn (2006). Flood forecasting, WMO Bulletin 55(3): 179-184.

Vaze, J., P Barnett, GTH Beale, W Dawes, R Evans, NK Tuteja, B Murphy, G Geeves, M Miller (2004). Modelling the effects of landuse change on water and salt delivery from a catchment affected by dryland salinity in south-east Australia, Hydrological Processes, 18:1613 - 1637.

Vicens, G., I Rodriquez-Iturbe, T Schaake (1975). A Bayesian framework for the use of regional information in hydrology, Water Resources Research, 11(3):405-415.

Welsh, W, J Vaze, D Dutta, D Rassam, J Rahman, I Jolly, P Wallbrink, G Podger, M Bethune, MJ Hardy, J Teng, J Lerat (2011). An integrated modelling framework for regulated river systems, Environmental Modelling \& Software (under review). 